\title{
Agreements and disagreements between children and their parents in health-related assessments
}

\author{
Helena Hemmingsson ${ }^{a}$, Linda Björk Ólafsdóttir ${ }^{b}$ and Snæfrídur Thóra Egilson ${ }^{b}$ \\ ${ }^{a}$ Department of Social and Welfare Studies, Linköping University, Linköping, Sweden; ${ }^{b}$ Faculty of Social and Human Sciences, University of \\ Iceland, Reykjavik, Iceland
}

\begin{abstract}
Purpose: To systematically review research concerning parent-child agreement in health-related assessments to reveal overall agreement, directions of agreement, and the factors that affect agreement in ratings.

Method: The Uni-Search and five additional databases were searched. Children's health issues were grouped into psychosocial issues including autism and ADHD, and physical and performance issues including pain. Measures used for comparison were those addressing (a) psychosocial functioning, (b) physical and performance functioning, and (c) health-related quality of life.

Results: Totally, 39 studies met the inclusion criteria, comprising 44 analyses in all since four studies contained more than one analyses. Moderate child-parent agreement was demonstrated in 23 analyses and poor agreement in 20 analyses. Several analyses found more agreement on observable/external than on non-observable/internal domains. Overall, parents considered their children had more difficulties than did the children themselves, although there were indications that for children with physical performance issues, parents may underreport their children's difficulties in emotional functioning and pain. There were no consistencies in differences between children's and parent's ratings on levels of agreement with respect to the children's health issue, age or gender.
\end{abstract}

Conclusions: Discrepancies between child and parent reports seem to reflect their different perspectives and not merely inaccuracy or bias.

\section{ARTICLE HISTORY}

Received 4 June 2015 Revised 4 April 2016

Accepted 10 May 2016

Published online 3 June 2016

\section{KEYWORDS}

Children's view;

concordance; $\mathrm{HR}(\mathrm{QoL})$;

physical functioning;

psychosocial functioning;

systematic review

\section{> IMPLICATIONS FOR REHABILITATION}

- In general, parents consider their children to have more difficulties - or more extensive difficulties than the children themselves think they have.

- The perspectives of the child and his or her parents should be sought whenever possible since both constitute important information concerning the child's health and well-being.

- Children with physical and performance issues reported more difficulties than their parents concerning the children's emotional functioning and pain.

- Clinicians should prioritize obtaining children's views on subjective aspects such as emotional issues as well as on pain.

\section{Introduction}

Previously, parents were considered to have knowledge and understanding of their children's thoughts, feelings and activities and were thus thought to accurately represent their children in health-related issues. This conception has been challenged during the past few years as research has increasingly demonstrated that the views of children and their parents may differ.[1-4]

The agreement between children's and their parents' reports has been explored to some extent with regard to specific issues such as (health-related) quality of life ((HR)QoL) [2,5] and pain [6] as well as psychosocial functioning.[7,8] The results of these studies demonstrate that overall, parents seem to be better at reporting what their child does (objective information) rather than how they are feeling or doing (subjective information). Nevertheless, certain gaps remain since, to our knowledge, no systematic research has been conducted to explore the concordance and discrepancy between the views of children with various types of health issues and their parents over a range of health-related assessments. $[9,10] \mathrm{A}$ variety of measures are used in paediatric settings, focusing on different aspects of children's health, such as physical performance functioning, psychosocial function, pain as well as (HR)QoL. The question remains of whether parent-child agreement is stronger in some domains or for some health issues than others. Hence, it is important to analyse in more detail whether and how the views of children and their parents may differ.

Good parent-child agreement indicates a high concordance between parent's and child's rating. Conversely, low or moderate parent-child agreement indicates a discrepancy in ratings which either reflects that parents report more difficulties or lower (HR)QoL of their children than the children themselves do, or that children report more difficulties or lower (HR)QoL than their parents do. In addition, there may be a discrepancy in parentchild ratings without any specific direction of the observed 
differences Thus, not only is the level of agreement interesting, but the direction of any disagreement also provides valuable information.

The aim of this study is to systematically review research concerning parent-child agreement as well as the similarities and differences between children with health issues and their parent's ratings with respect to physical and psychosocial function, pain and (HR)QoL in health-related assessments. The following four research questions were posed:

1. How is the overall agreement between parents and their children in health-related assessments?

2. In which domains do parents report more difficulties with respect to physical and psychosocial functioning and pain or lower (HR)QoL of their children than the children themselves?

3. In which domains do children report more difficulties with respect to physical and psychosocial functioning and pain or lower (HR)QoL than their parents do as regards their children?

4. Which factors (i.e., age, gender, health issues or functional limitations) affect agreement in ratings?

\section{Materials and methods}

\section{Literature search}

The Preferred Reporting Items for Systematic Reviews and Metaanalyses (PRISMA) [11] were used as a guide for structuring the search and reporting the systematic review. Inclusion criteria were: (a) primary research concerning agreement between parents and their children $(n \geq 20)$ with health issues or functional limitations, in health-related assessments including (HR)QoL, (b) published in English-language peer-reviewed journals from January 2000 to June 2015, (c) age of children 5-18 years, (d) use of the same measure by parent and child, or parent and child version of the same measure.

Exclusion criteria were: studies about children with dyslexia, asthma or allergy, epilepsy or eating disorders. In addition, studies where parent's health issue was in focus (i.e., comparing children's ratings with that of their depressive parents), literature reviews, meta-analyses, studies focusing primarily on the psychometric properties of measures or those which did not provide sufficient statistics on the level of parent-child agreement were also excluded.

The database Uni-Search which covers a broad range of databases was approached. The following disciplines were chosen: health and medicine, complementary and alternative medicine, nursing and allied health, physiotherapy and occupational therapy, public health, psychology and social work. Search words used were the combination of parent and child $A B(A B=$ abstract $)$ AND agreement $A B$ OR concordance $A B$ AND assessment $A B$. NOT asthma, NOT allergy, NOT weight, NOT eating disorder, NOT epilepsy, NOT review. The expanders used were: (a) apply-related words, and (b) also search within the full text of the articles. The database search resulted in 348 articles. Duplicates were automatically removed by Uni-Search. All titles and, when needed, abstracts were scanned to exclude studies that did not fulfil the inclusion criteria $(n=166)$. Thereafter, the remaining 182 abstracts were read in detail, resulting in 60 studies, as illustrated in Figure 1.

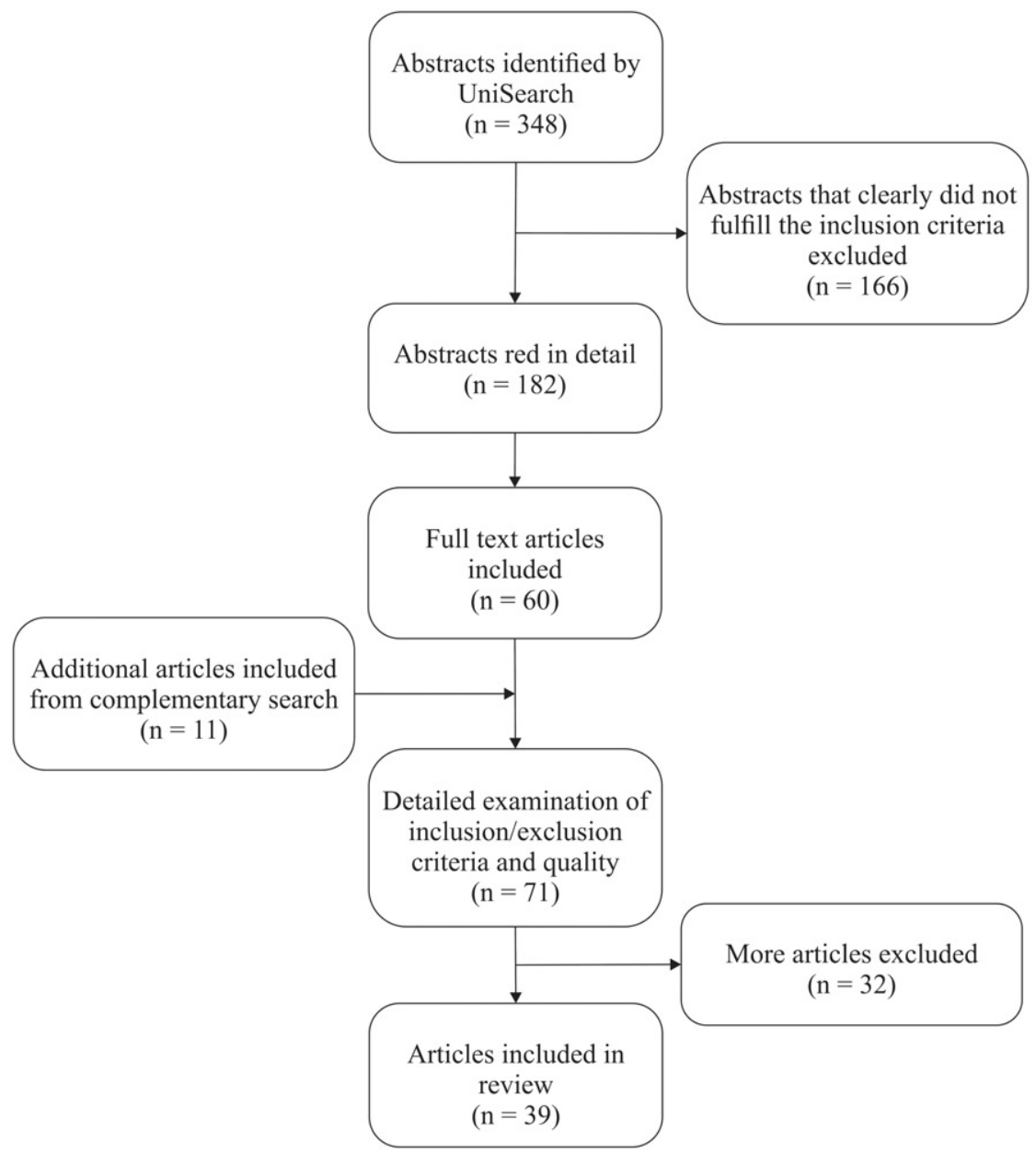

Figure 1. Flow-chart showing the process of identifying and selecting articles included. 
As Uni-Search is a relatively new option for literature searches, a complementary search was performed of the databases CINAHL, ERIC, MEDLINE (Ovid), AMED and PsycINFO in order to validate the findings. The same inclusion and exclusion criteria, search limitations, search words and expanders were used as described above. This search resulted in 515 abstracts which were screened by the first author. Duplicates from Uni-Search were removed. Fifty studies were then selected for reading abstracts in detail and, if needed, the full article. This complementary search produced seven studies that had not been found earlier. Finally, the reference lists in the included articles were scanned, resulting in the identification of four more studies.

Thus, a total of 11 studies were added to the initial search outcome in, resulting in altogether 71 studies that were read and examined in detail, in line with the inclusion/exclusion criteria as well as for quality and rigour of methodology and statistics used.[11] Of the 71 studies, 32 were rejected based on one or more of our exclusion criteria because they involved healthy children $(n=16)$, did not use valid or identical measures for child and parent $(n=8)$, the child-parent assessments were inadequately paired $(n=6)$, the focus was primarly on psychometric properties $(n=4)$ or the statistics were insufficient $(n=6)$, resulting in 39 studies included in the final review. Figure 1 shows a flowchart of the study selection process.

\section{Data extraction and analyses}

All articles were read by the authors, typically in detail by one author and more briefly by the others. Subsequently, they were cross-checked for errors and omissions. For each study the following information was extracted: information about authors, title, year of publication, country of origin, children's health issues (grouped into psychosocial issues [PSI] including autism and $A D H D$, and physical and performance issues [PPI] including pain), children's age, number of child-parent pairs, variables of concern for the investigation, measure(s) used, and statistical analyses conducted (Table 1). Extracted data were then organised in a matrix as suggested by Aveyard.[12]

The analyses proceeded with categorisation of the measures used in three types depending on the variables of concern: (a) those addressing psychosocial functioning including anxiety and autonomy, (b) those addressing physical and performance functioning and issues including pain; and (c) those including a broad range of children's functioning and well-being such as their (HR)QoL. The measures used were then related to the children's health issues to identify patterns (Table 2).

Next, the studies were analysed according to our aim and the four research questions. First, overall agreement as reported in each study was categorised as poor, moderate/reasonable or strong. In order to compare the level of overall agreement, the statistics used in each article were examined.

Although strong correlations between child and parent proxy data demonstrate some validity, they do not ensure that the two ratings are interchangeable in terms of mean values.[13] Thus, ideally, intraclass correlation coefficients should be used instead of Pearson.[14] In this review all but six studies used ICC and/or kappa statistics. Some of these provided guidelines for how to interpret the statistics while others did not. Most authors using ICC categorised the strength of agreement into four levels, but these varied in definition. Due to this variation and in order to be able to compare the overall agreement across studies, we decided to use classification in three levels as described by Sturms et al. [15] Thus, the strength of agreement reflected by ICCS was classified as follows: ICC below 0.50 was poor agreement; ICC $=0.50$ to 0.79 was moderate agreement; and ICC over 0.80 was strong agreement. The same categorisation was used for the Pearson correlation coefficient when applicable.

Interpretation of kappa statistics was based on Landis and Koch,[16] and thus values below 0.40 were considered poor; values 0.40-0.59 were fair; values 0.59-0.79 were good, and values of 0.80 or greater were considered excellent. For the purpose of this study, we merged fair and good, resulting in three categories: below 0.40 was poor; 0.40 to 0.79 was moderate; and values over 0.80 were excellent. The guiding principle for our classification was that ICCs were used for comparison if present $(n=22)$, the second choice was kappa statistics $(n=11)$ and thereafter other statistics including Pearson $(n=6)$.

Next, the analyses proceeded to item level and direction of agreement to identify: (a) in which domains do children report more difficulties or lower (HR)QoL than their parents do as regards their children? and (b) in which domains do parents report more difficulties or lower (HR)QoL of their children than the children do themselves?

Finally, we focused on child characteristics (age, gender, diagnosis or level of impairment) which might influence agreements in ratings.

\section{Results}

A total of 39 studies met the inclusion criteria; these are presented in Table 1. The countries of origin were as follows: 20 studies were conducted in the USA, 12 in Europe $(U K=3$, Sweden $=3$, Netherlands $=3$, France =1, Switzerland =1, and Serbia=1) 3 in Australia, 2 in Canada and one respectively in Taiwan and Korea. The number of dyads (children and parents) in each study ranged from 22 to 2153. In 19 studies the number of dyads was below 100 , and in six studies the number was above 400 . In total, this review consists of 10,520 dyads.

The 39 studies altogether reported on 44 analyses of parent-child agreement which are the base for this review. As Table 2 shows 17 studies exclusively concerned children with PSI and 21 studies concerned children with PPI. Although one of these, by Vroland-Nordstrand and Krumlinde-Sundholm,[17] had a mixed group, it was categorised as PPI because physical health issues were in the majority. In addition, one study by Dey et al. [18] comprised both groups with separate analyses of parent-child agreement for each group. The studies typically used one measure each for the child-parent comparison with the exception of Brunner et al., [19] Cohen et al. [6] and Gutierrez-Colina et al. [20] Brunner et al. [19] included both assessment of (HR)QoL and of pain in children with chronic arthritis (physical and performance functioning); Cohen et al. [6] included assessment of pain and functional disability; and Gutierrez-Colina et al. [20] assessed both (HR)QoL and psychosocial functioning. In addition, Murray et al. [21] reported two analyses with the same measure but at different time points.

Table 2 also shows children's health issues, level of parent-child agreement and type of assessments used. Analyses which addressed parent-child agreement mostly focused on (HR)QoL and psychosocial functioning. For children with PPI, parent-child agreement was mostly assessed in relation to (HR)QoL $(n=16)$; seven analyses concerned physical and performance functioning and two focused on psychosocial functioning. For children with PSI, altogether 13 analyses addressed child-parent agreement on psychosocial functioning. Six analyses focused on child-parent agreement on (HR)QoL and none addressed physical and performance functioning. 


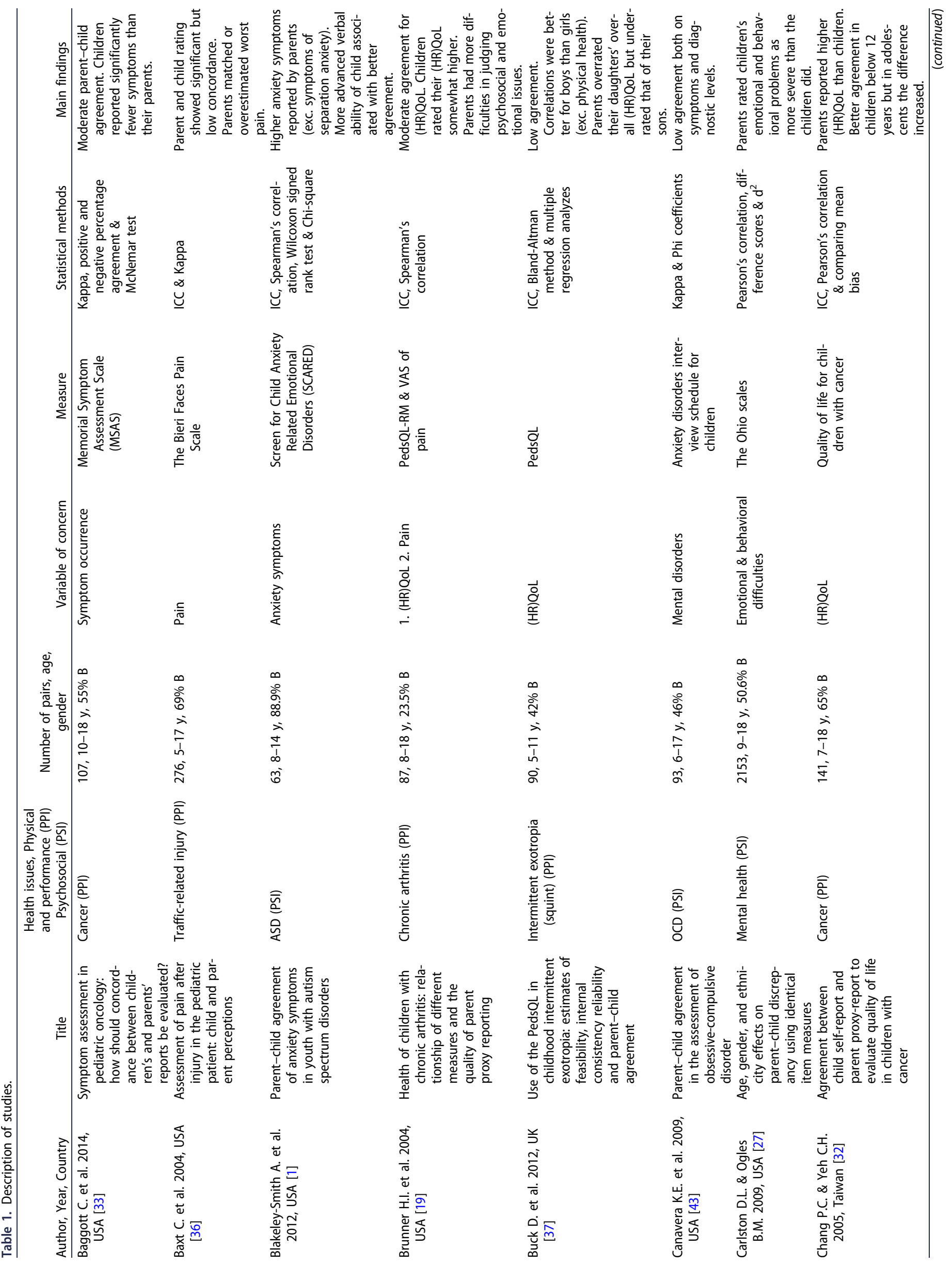




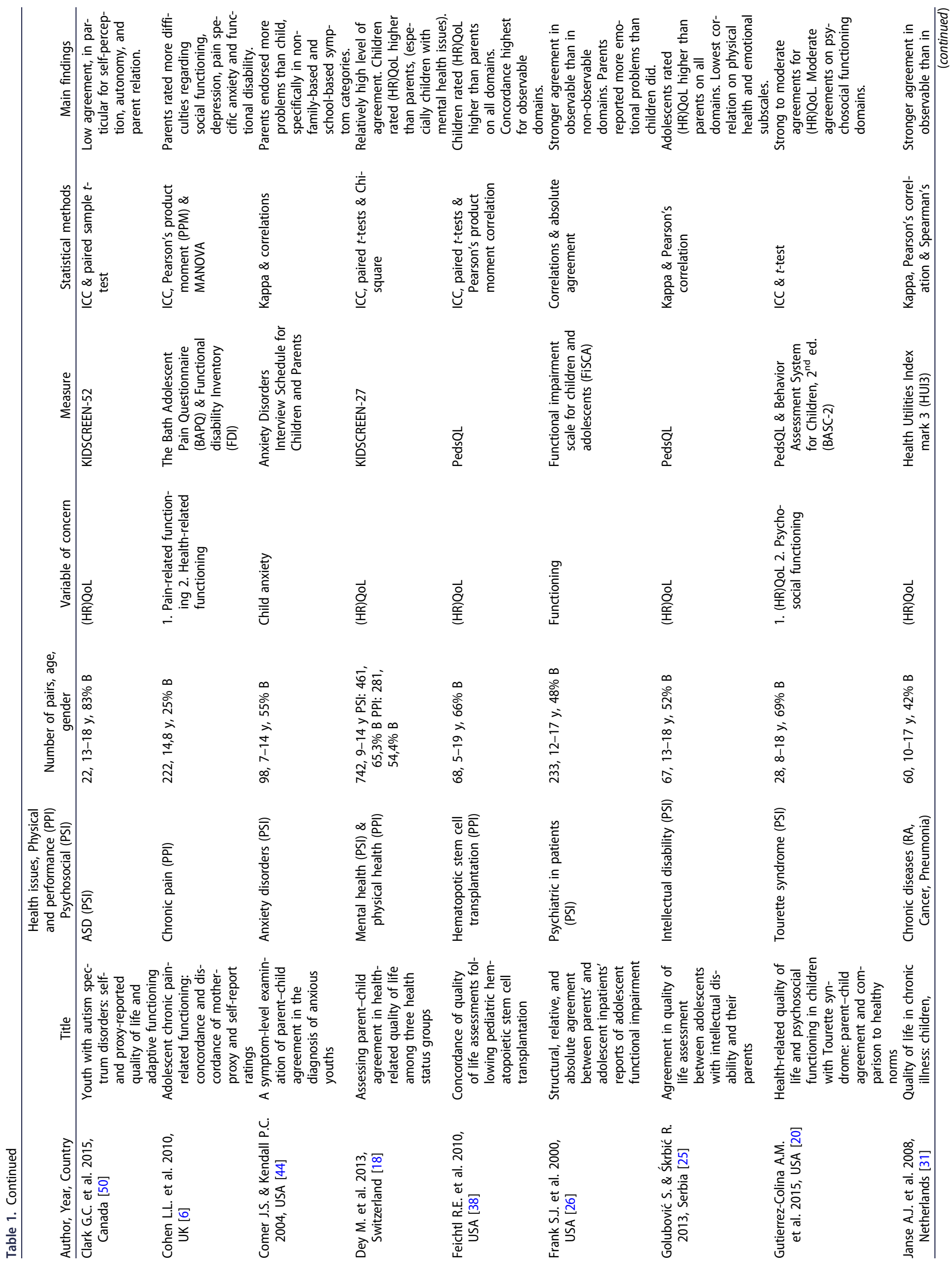




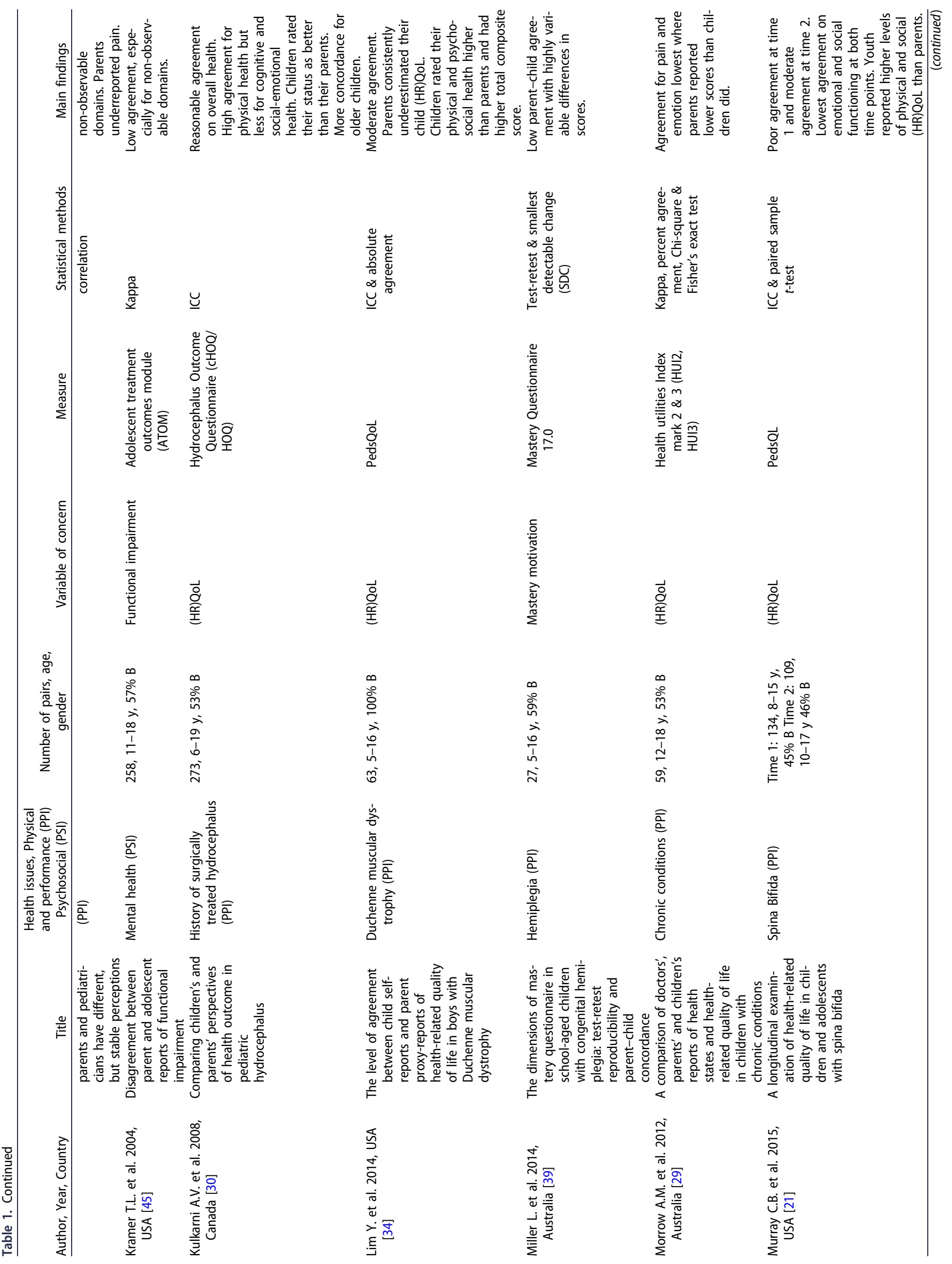




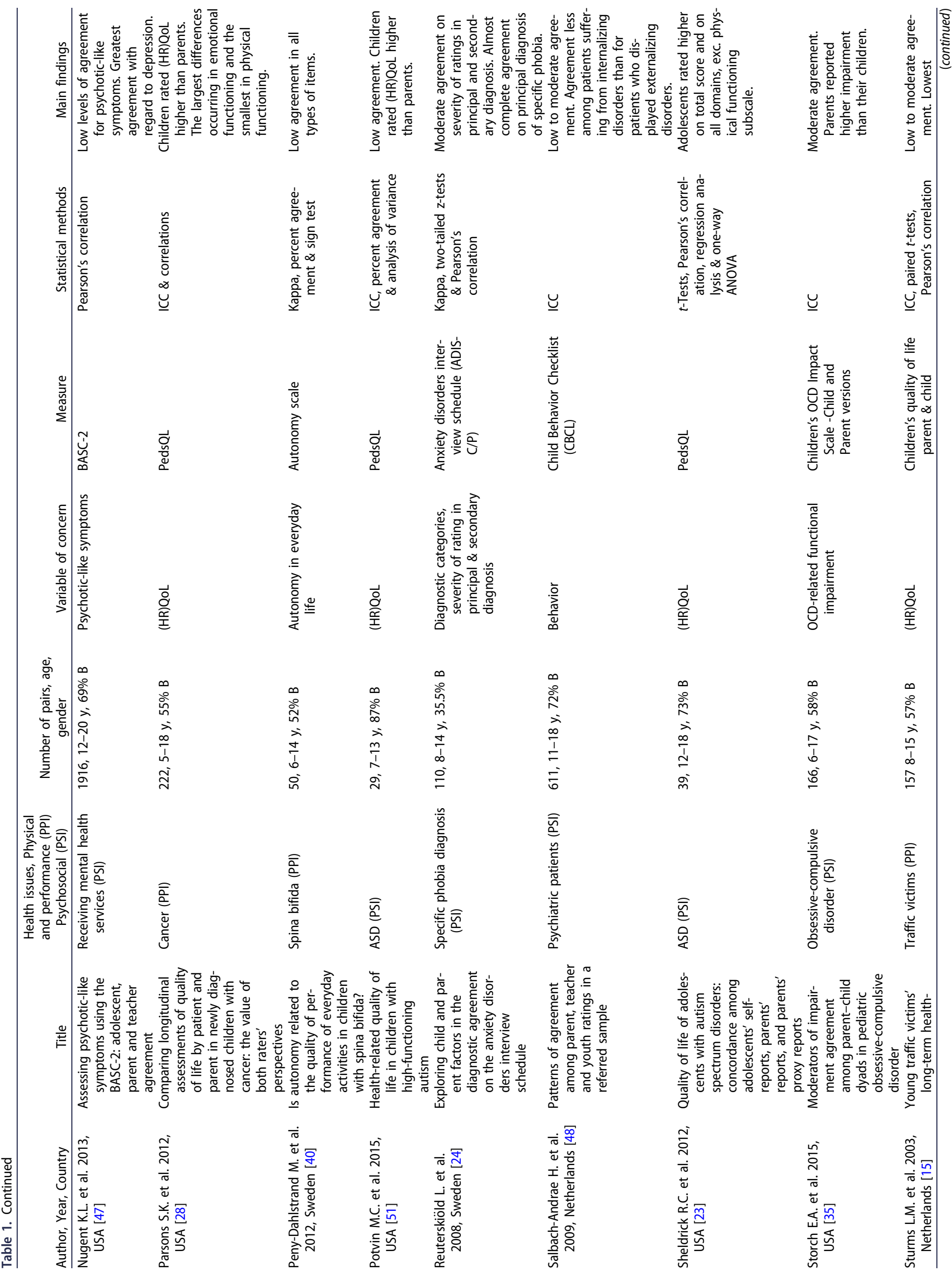




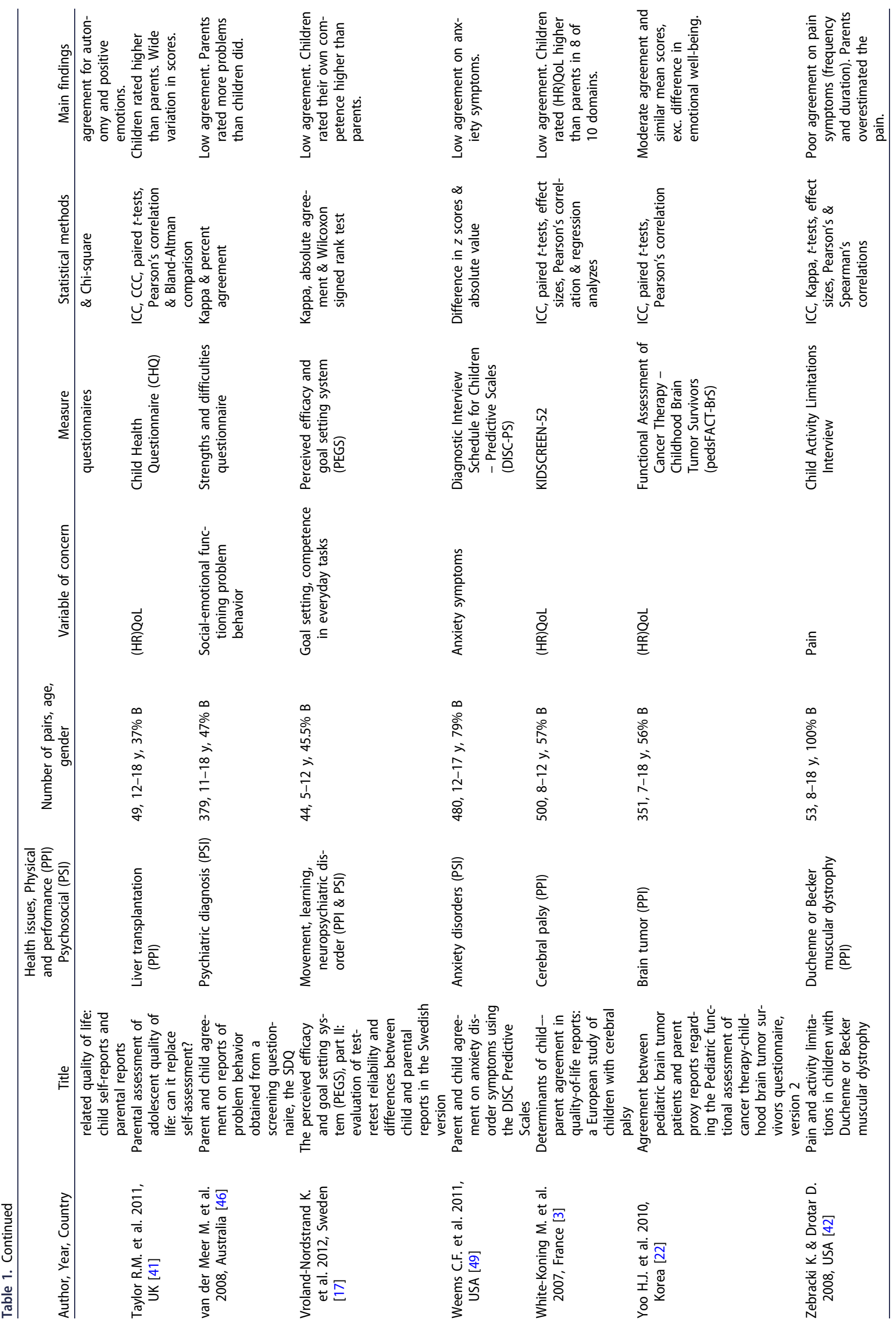




\section{Overall agreement between parents and their children}

Table 2 demonstrates that according to our classification, an overall, strong parent-child agreement was found in only one of the analyses included in this review. Gutierrez-Colina et al. [20] found strong parent-child agreement in (HR)QoL. In addition, one analysis by Yoo et al. [22] with overall moderate agreement showed strong agreement for children aged 7-12 years but less for children aged 13-18 years. Moderate overall agreement was demonstrated in 23 analyses [1,6,15,18-35] and poor agreement in 20 analyses.[3,17,19,21,36-51] There were no differences between the levels of agreement with respect to children's health issues, as shown in Table 2. In about half of the analyses, parent-child agreement was moderate, and poor in the other half, irrespective of the children's health issue.

In line with earlier research, several studies found more agreement on observable/external symptoms and domains than on non-observable/internal. [6,19,24,26,28-31,38,44-46,48] However, there were also examples of the opposite.[27,43] For example, in a sample of children with mental health problems, Carlston and Ogles [27] found that parent and child did not differ significantly in their reports on internalizing problems, while parents reported greater levels of child externalizing behaviours than did their children.

\section{Direction of observed differences between parents and their children}

Parents report more difficulties or lower (HR)QoL

Some studies reported the direction on differences where either the parent or the child reported more difficulties in one or more domain (Table 3). In 25 analyses, parents considered their children as having more difficulties (or more severe difficulties) than did the children themselves in one or more domains. $[1,3,6,17,18,20,21,23,25-28,30,33,35,36,38,39,41,42,44-46$, $48,51]$ The domains identified were psychosocial functioning,[1,6,26-28,44-46,48] pain,[6,36,42] school work,[28,42,44] physical functioning and performance competence $[6,17,39,42]$ such as turning in bed, climbing the stairs and doing housework [42] and number of symptoms.[33] In addition, parents typically reported lower overall (HR)QoL of their children $[3,18,23,25,28,30,38,50,51]$ than the children themselves did.

Children report more difficulties or lower (HR)QoL

Fourteen analyses were identified in which children reported more difficulties than their parents in one or more domains.[3,15,19, $20,22,25,26,29,31,32,37,39,40,45]$ Four of these analyses concerned young people with PSI and 10 concerned children with PPI. Domains in which children with PPI reported more difficulties were emotional functioning,[15,19,22,29,32,37,39] pain,[3,29,31,37] motor functioning,[15] physical complaints [15] and autonomy.[15,40] Domains in which young people with PSI were somewhat more likely to report problems were use of alcohol and drugs,[26] social functioning [25] and legal consequences of bad behaviour.[26,45]

\section{Factors that influence agreement in ratings}

Just about half of the studies (18/39) searched for factors that were associated with discrepancies in parent-child agreement, such as children's age, gender or functional limitations.

Age

Eight analyses reported that the discrepancy in ratings was not related to the children's age,[19,27,36-38,43,46] but contradictory results were also found.[6,22,28,30,32,43] For example, Cohen et al. [6] found that higher age was associated with greater concordance in scores for social functioning, depression and pain-specific anxiety. Likewise, Kulkarni et al. [30] found the agreement of parent and child to be significantly lower for the youngest children in their study, in particular for physical and school function. In contrast, Yoo et al., [22] Chang and Yeh,[32] and Canavera et al. [43] found greater parent-child agreement among young children and their parents compared to adolescents.

\section{Gender}

Inconsistent results were reported concerning whether or not parent-child agreement was related to the child's gender. Parent-child agreement was not associated with children's and adolescent's gender according to Brunner et al., [19] Baxt et al., [36] and Canavera et al. [43]

Two studies found higher parent-child agreement in girls than in boys based on whether or not they had a specific diagnosis [24] or problems.[46] In contrast, Carlston and Ogles [27] demonstrated greater discrepancies on fewer specific items for parent's and daughter's ratings while parents and sons demonstrated more pervasive but less severe discrepancies. Cohen et al. [6] reported that being a male was associated with parent-child agreement in social functioning. Buck et al. [37] found that parents overrated their daughter's overall QoL on the PedsQL and some aspects of psychosocial functioning but underrated that of their sons.

\section{Health issues or functional limitations}

Discrepancies in ratings associated with child's health issues or functional limitations were found in five analyses. Morrow et al. [29] found that for children with CP or chronic neurological conditions, there was a significantly increased chance of disagreement between responders for both subjective and objective domains. Baggott et al. [33] reported lower parent-child agreement for children with acute lymphoblastic leukemia compared to other types of cancer. Storch et al. [35] reported stronger parent-child agreement for children who demonstrated greater Obsessive-compulsive disorder symptoms compared to those with less symptoms. Salbach-Andrae et al. [48] reported lower levels of agreement for children who had internalising mental health issues, such as anxiety and somatoform disorders, than for adolescents who displayed externalizing disorders such as conduct disorders and ADHD. White-Koning et al. [3] found less disagreement between parent and child when the child had lower IQ and lower ability to communicate. However, Baxt et al., [36] Brunner et al., [19] and Feichtl et al. [38] did not find any associations between discrepancies in ratings and children's health issues or functional limitations.

\section{Discussion}

The overall agreement between children and their parents in this review, in general, was either moderate/medium (23 analyses) or poor (20 analyses). Strong agreement was only found in one analysis.[20] Interestingly, there were no differences between levels of agreement with respect to children's health issues as our investigation demonstrated no overall difference between children with PPI and children with PSI.

In line with earlier research $[9,10,52]$ we found more child-parent agreement on observable or external symptoms and behaviours than on non-observable domains, such as feelings and emotions. Overall, parents seemed to report more accurately what their child did rather than how they were doing or feeling. This is not surprising given the fact that children's subjective experiences 


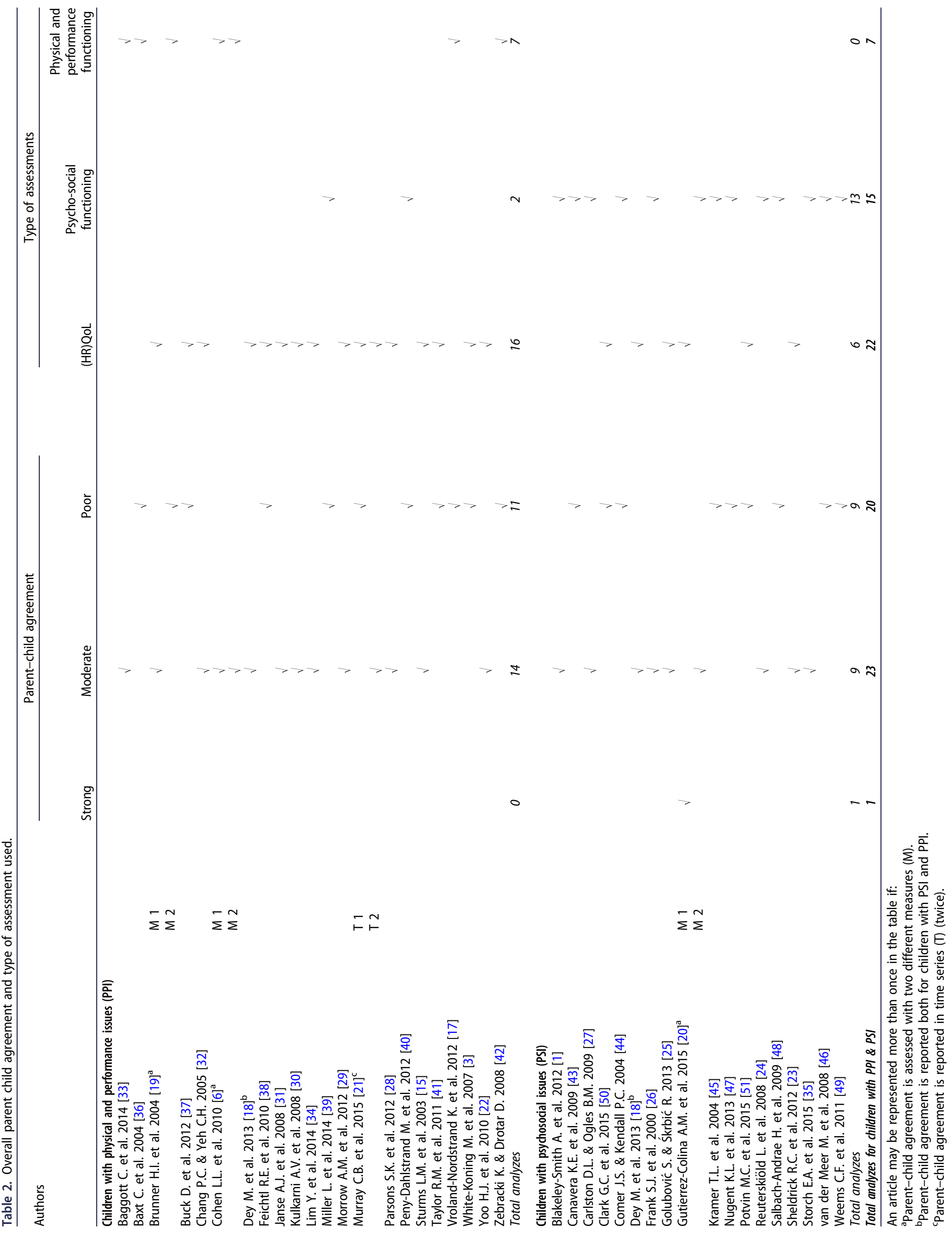


Table 3. Direction of disagreement in one or more domain.

\begin{tabular}{|c|c|c|c|}
\hline \multirow{2}{*}{ Children's health issues } & \multicolumn{3}{|c|}{ Parent-child agreement } \\
\hline & Parents report more difficulties & Children report more difficulties & Total \\
\hline Physical and performance health issues & $\begin{array}{l}12 \text { analyses } \\
\text { Baggott C. et al. } 2014 \text { [33]; Baxt C. et al. } 2004 \\
\text { [36]; Cohen L.L. et al. } 2010 \text { [6]; Feichtl R.E. et al. } \\
2010 \text { [38]; Kulkarni A.V. et al. } 2008 \text { [30]; Miller L. } \\
\text { et al. 2014 [39]; Murray C.B. et al. } 2015 \text { [21]; } \\
\text { Parsons S.K. et al. } 2012 \text { [28]; Taylor R.M. et al. } \\
2011 \text { [41]; Vroland-Nordstrand K. et al. } 2012 \text { [17]; } \\
\text { White-Koning M. et al. } 2007 \text { [3]; Zebracki K. \& } \\
\text { Drotar D. } 2008 \text { [42] }\end{array}$ & $\begin{array}{l}10 \text { analyses } \\
\text { Brunner H.I. et al. } 2004 \text { [19]; Buck D. et al. } 2012 \\
\text { [37]; Chang P.C. \& Yeh C.H. } 2005 \text { [32]; Janse A.J. } \\
\text { et al. } 2008 \text { [31]; Miller L. et al. } 2014 \text { [39]; Morrow } \\
\text { A.M. et al. } 2012 \text { [29]; Peny-Dahlstrand M. et al. } \\
2012 \text { [40]; Sturms L.M. et al. } 2003 \text { [15]; White- } \\
\text { Koning M. et al. } 2007 \text { [3]; Yoo H.J. et al. } 2010 \\
\text { [22] }\end{array}$ & 22 \\
\hline Psychosocial health issues & $\begin{array}{l}13 \text { analyses } \\
\text { Blakeley-Smith A. et al. } 2012 \text { [1]; Carlston D.L. \& } \\
\text { Ogles B.M. } 2009 \text { [27]; Comer J.S. \& Kendall P.C. } \\
2004 \text { [44]; Dey M. et al. } 2013 \text { [18]; Frank S.J. } \\
\text { et al. 2000 [26]; Golubović S. \& Śkrbić R. } 2013 \\
\text { [25]; Gutierrez-Colina A.M. et al. } 2015 \text { [20]; } \\
\text { Kramer T.L. et al. } 2004 \text { [45]; Potvin M.C. et al. } \\
2015 \text { [51]; Salbach-Andrae H. et al. } 2009 \text { [48]; } \\
\text { Sheldrick R.C. et al. } 2012 \text { [23]; Storch E.A. et al. } \\
2015 \text { [35]; van der Meer M. et al. } 2008 \text { [46] }\end{array}$ & $\begin{array}{l}4 \text { analyses } \\
\text { Frank S.J. et al. } 2000 \text { [26]; Golubović S. \& Śkrbić } \\
\text { R. } 2013 \text { [25]; Gutierrez-Colina A.M. et al. } 2015 \\
\text { [20]; Kramer T.L. et al. } 2004 \text { [45] }\end{array}$ & 17 \\
\hline Total & 25 & 14 & 39 \\
\hline
\end{tabular}

do not directly affect others and may be less noticeable than behaviours that have direct consequences for their family members. Parents are likely to have more knowledge about what they have observed or experienced than about their children's feelings and thoughts, since the latter may not always be communicated to parents. Parents are also less likely to have thorough information about their child's well-being in situations where they themselves are not present, such as in school and in certain community settings. Upton et al. [2] noted that closely correlated child and parent perceptions of the health status of children with specific health issues may in fact reflect high levels of parental involvement in these particular issues.

In general, parents consider their children to have more difficulties (or more extensive difficulties) than the children themselves think they have. Nevertheless, of specific interest are those domains where children reported more difficulties or lower (HR)QoL than parents (14/39 analyses) as children's opinions are not always elicited in paediatric settings and instead their parents are the main informants. It is noteworthy that our results indicate that emotional challenges and pain may be underreported by parents of children with PPI.

Although children occasionally reported lower scores than their parents in some domains on measures focusing on (HR)QoL, they typically did not rate their overall (HR)QoL as low or lower than their parents. In eleven analyses, parents reported lower (HR)QoL of their children than the children did themselves. Conversely, Chang and Yeh [32] reported higher (HR)QoL by parents than by their children who had cancer, and Buck et al. [37] found that parents of children with intermittent exotropia overrated their daughters' overall (HR)QoL but underrated that of their sons.

In addition to health issues and functional limitations of the child, we also did not find any consistent data demonstrating discrepancies associated with children's age or gender. This indicates that the discrepancies found in general resulted from the two different perspectives, parent and child. As reported earlier, parents often report more difficulties or lower (HR)QoL of their children than the children themselves. Carlston and Ogles [27] provided an explanation for this discrepancy by referring to the Attribution Bias Context model by De Los Reyes and Kazdin.[53] According to this model, parents are more likely, as observers, to attribute child behaviour to the child's disposition rather than to the environment. In contrast, children are more likely, as actors, to attribute symptoms to the environment. Thus, parents tend to report a greater number of child symptoms relative to their children and also to see their child's behaviour as more problematic than the children themselves. Another study found that children, more than their parents, seem to base their responses on a single example.[54] The difference between children's and their parent's answers may thus reflect their different reasoning and response styles, as well as their different understanding and interpretation of questions and items.[8,53,55]

\section{Measures and methodology}

The articles in this review made use of different measures, which may have affected the results, although we could not explore this specifically due to confounding factors such as different sample characteristics, age distinctions and variations in the forms of statistical analyses used. Nevertheless, good agreement between children and their parents may possibly reflect the "observable" nature of the items of the measures being used, even when the focus is on the same construct. For example, a comparison of two of the measures focusing on (HR)QoL in this review, the PedsQL $[19-21,23,25,28,37,38,51]$ and the KIDSCREEN,[3,18,50] revealed that a majority of the items in the PedsQL are framed in a rather objective manner and thus concern what children can do, rather than how they feel. In contrast, the items in the KIDSCREEN are more subjective in nature. Thus, the choice of measure may have implications for the concordance between parents and children on the construct of (HR)QoL. Since only three studies in this review used the KIDSCREEN, it was not possible to explore this idea further.

Due to methodological differences between studies, we experienced some challenges, and on occasions there were substantial variations in agreement between children's and parents' responses depending on the method of analyses used. For example, Taylor et al. [41] found significant correlations in every domain of the Child Health Questionnaire (CHQ) when using Pearson correlation coefficients; however, there were no ICCs at or above 0.80 , suggesting only limited or moderate agreement. The Bland-Altman comparison indicated wide variation in the $95 \%$ limits of agreement. We chose ICCs for our comparison if present, as this statistic 
takes into account both the variations in rank order of the scores in different groups as well as variations in the magnitude of the difference in scores.[2,14,56] It should be noted that there are different ways to estimate ICCs.[14,57] In our analyses we were not able to use one unified approach as we had to rely on the information provided by authors. This is a limitation to our study.

Parent-child-agreement can be assessed either at the individual level (such as by correlation) or at the group level (such as by comparing means). As pointed out by Upton et al., [2] correlations may be high even when absolute agreement is low. GutierrezColina et al. [20] found strong, positive relationships between child self- and parent proxy-reports on all PedsQL domains, but $t$-tests revealed significant differences between children and their parents ratings on the physical health subscale. In the study by WhiteKoning et al., [3] correlation was lowest in the subjective emotions and parental relations domains of the KIDSCREEN 52, and higher in the more objective social acceptance and social support domains. Nevertheless, the emotions domain had the second highest rate of agreement, whereas social support had one of the lowest rates. The factors that affected parent-child disagreement in that particular study were not the same depending on the direction of differences, which emphasizes the relevance of separately studying whether parents report higher or lower (HR)QoL than the children themselves. Also, Carlston and Ogles [27] found that the manner in which gender impacts discrepancy among children and their parents on child behaviour and emotional functioning varied as a function of the type of discrepancy analysed.

In order to perform complicated analyses, a large number of participants are required. Almost half of the studies in this review had fewer than 100 parent-child dyads, and only six articles had over 400 dyads. Thus, many studies did not have sufficient numbers of participants to separately examine predictors of parentchild agreement as well as the direction of observed differences.

One more methodological aspect worth noting is the perspective used in the report. Typically, the term "proxy-report" indicates that another individual (in this case the parent) is asked to answer as he or she thinks their child would answer. Nevertheless, several authors used the term "proxy" without defining it specifically. Thus, it is possible that the parents in some studies actually reported on their own perceptions of their child (standard parent report) rather than as they thought their child would answer. One study used both types of parent reports and found higher correlations between parent-proxy reports and adolescent self-reports than between standard parent reports and adolescent selfreports.[23] In addition, average scores on the parent-proxy reports in that study were closer to the adolescents' self-reports than were average scores on the standard parent reports. Thus, parent's standard reports seem to provide a less accurate view of the child's opinion of health issues than if parents are asked explicitly to answer based on their assumption of what their child would report.

\section{Conclusion}

We would like to stress that the discrepancies between child and parent reports seem to reflect their different perspectives and not merely inaccuracy or bias. The discrepancies appear to be consistent, since neither children's health issues, their age nor gender appear to influence the rather poor parent-child agreement obtained. Since the publication of the UN Convention on the Rights of the Child in 1989 [58] the importance of eliciting children's views has been increasingly stressed. An emphasis is placed on respect for the views of children, their right to express their opinions freely on all matters affecting them, and to have those opinions taken seriously. Research involving children's perspectives has now reached the point of being accepted as a field of study, but there are indications that this may not apply to the same extent in actual practice.

Although we believe children's views should be sought whenever possible, we acknowledge that there may be a need for a multi-informant approach in the assessment of childhood health issues. Parent proxy-reports are often necessary to supplement and provide complementary information to that collected from their children. They may also be used as a substitute when it is not possible to obtain reports directly from children due to their low age, or severe intellectual or physical impairment.[59] Since disagreement between children and their parents appears to be less frequent when the child has lower IQ or lower ability to communicate, it may seem reasonable to rely more on parental proxyreports in such cases.[3,25]

Ideally, the perspectives of both the child and their parents should be sought whenever possible. The conceptual basis for this conclusion is that children and parents have different perspectives on the child's life, both of which are valid and constitute important information concerning the child's health and well-being.[3,4,53]

The information on parent-child concordance on health issues provided in this study is important with respect to the choice of measures to be used as a foundation for decision-making in paediatric settings and in order to provide relevant and best possible intervention. Based on the results, we strongly recommend using measures that include both parents' and children's views. The results also provide guidelines for interpreting results when only parents are asked. Our investigation demonstrated that children with PPI reported more difficulties than their parents on the children's emotional functioning and pain. These domains are of the utmost importance for children's health and wellbeing. Based on these findings, we suggest that clinicians prioritise obtaining children's views on subjective matters such as emotional issues as well as on pain.

\section{Disclosure statement}

The authors report no conflicts of interest.

\section{References}

[1] Blakeley-Smith A, Reaven J, Ridge K, et al. Parent-child agreement of anxiety symptoms in youth with autism spectrum disorders. Res Autism Spectr Disord. 2012;6:707-716.

[2] Upton P, Lawford J, Eiser C. Parent-child agreement across child health-related quality of life instruments: a review of the literature. Qual Life Res. 2008;17:895-913.

[3] White-Koning $M$, Arnaud $C$, Dickinson $\mathrm{HO}$, et al. Determinants of child-parent agreement in quality-of-life reports: a European study of children with cerebral palsy. Pediatrics. 2007;120:804-814.

[4] Egilson ST, Ólafsdóttir LB, Leósdóttir T, et al. Quality of life in high-functioning children and youth with autism spectrum disorder and typically developing peers: self- and proxy-reports. Autism. 2016. [Epub ahead of print]. doi: $10.1177 / 1362361316630881$.

[5] Rajmil L, Lopez AR, Lopez-Aguila S, et al. Parent-child agreement on health-related quality of life (HRQOL): a longitudinal study. Health Qual Life Outcomes. 2013;11:101-111.

[6] Cohen LL, Vowles KE, Eccleston C. Adolescent chronic painrelated functioning: concordance and discordance of 
mother-proxy and self-report ratings. Eur J Pain. 2010;14:882-886.

[7] van der Ende J, Verhulst FC, Tiemeier H. Agreement of informants on emotional and behavioral problems from childhood to adulthood. Psychol Assess. 2012;24:293-300.

[8] Van Roy B, Groholt B, Heyerdahl S, et al. Understanding discrepancies in parent-child reporting of emotional and behavioural problems: effects of relational and socio-demographic factors. BMC Psychiatry. 2010;10:56-68.

[9] Varni JW, Burwinkle TM, Sherman SA, et al. Health-related quality of life of children and adolescents with cerebral palsy: hearing the voices of the children. Dev Med Child Neurol. 2005;47:592-597.

[10] Klassen AF, Miller A, Fine S. Agreement between parent and child report of quality of life in children with attentiondeficit/hyperactivity disorder. Child Care Health Dev. 2006;32:397-406.

[11] Moher D, Liberati A, Tetzlaff J, et al. Preferred reporting items for systematic reviews and meta-analyses: the PRISMA statement. Int J Surg. 2010;8:336-341.

[12] Aveyard H. Doing a literature review in health and social care: A practical guide. 2nd ed. Maidenhead: Open University Press; 2010.

[13] Eiser C, Morse R. Can parents rate their child's health-related quality of life? Results of a systematic review. Qual Life Res. 2001;10:347-357.

[14] McGraw K, Wong S. Forming inferences about some intraclass correlation coefficients. Psychol Methods. 1996;1:30-46.

[15] Sturms LM, van der Sluis CK, Groothoff JW, et al. Young traffic victims' long-term health-related quality of life: child selfreports and parental reports. Arch Phys Med Rehabil. 2003;84:431-436.

[16] Landis JR, Koch GG. The measurement of observer agreement for categorical data. Biometrics. 1977;33:159-174.

[17] Vroland-Nordstrand K, Krumlinde-Sundholm L. The perceived efficacy and goal setting system (PEGS), part II: evaluation of test-retest reliability and differences between child and parental reports in the Swedish version. Scand J Occup Ther. 2012;19:506-514.

[18] Dey M, Landolt MA, Mohler-Kuo M. Assessing parent-child agreement in health-related quality of life among three health status groups. Soc Psychiatry Psychiatr Epidemiol. 2013;48:503-511.

[19] Brunner HI, Klein-Gitelman MS, Miller MJ, et al. Health of children with chronic arthritis: relationship of different measures and the quality of parent proxy reporting. Arthritis Rheum. 2004;51:763-773.

[20] Gutierrez-Colina AM, Eaton CK, Lee JL, et al. Health-related quality of life and psychosocial functioning in children with Tourette syndrome: parent-child agreement and comparison to healthy norms. J Child Neurol. 2015;30:326-332.

[21] Murray CB, Holmbeck GN, Ros AM, et al. A longitudinal examination of health-related quality of life in children and adolescents with spina bifida. J Pediatr Psychol. 2015;40:419-430.

[22] Yoo HJ, Ra YS, Park HJ, et al. Agreement between pediatric brain tumor patients and parent proxy reports regarding the pediatric functional assessment of cancer therapy-childhood brain tumor survivors questionnaire, version 2. Cancer. 2010;116:3674-3682.

[23] Sheldrick RC, Neger EN, Shipman D, et al. Quality of life of adolescents with autism spectrum disorders: concordance among adolescents' self-reports, parents' reports, and parents' proxy reports. Qual Life Res. 2012;21:53-57.

[24] Reuterskiöld L, Öst L-G, Ollendick T. Exploring child and parent factors in the diagnostic agreement on the anxiety disorders interview schedule. J Psychopathol Behav Assess. 2008;30:279-290.

[25] Golubović S, Skrbić R. Agreement in quality of life assessment between adolescents with intellectual disability and their parents. Res Dev Disabil. 2013;34:1863-1869.

[26] Frank SJ, Van Egeren LA, Fortier JL, et al. Structural, relative, and absolute agreement between parents' and adolescent inpatients' reports of adolescent functional impairment. J Abnorm Child Psychol. 2000;28:395-402.

[27] Carlston D, Ogles B. Age, gender, and ethnicity effects on parent-child discrepancy using identical item measures. J Child Fam Stud. 2009;18:125-135.

[28] Parsons SK, Fairclough DL, Wang J, et al. Comparing longitudinal assessments of quality of life by patient and parent in newly diagnosed children with cancer: the value of both raters' perspectives. Qual Life Res. 2012;21:915-923.

[29] Morrow AM, Hayen A, Quine S, et al. A comparison of doctors', parents' and children's reports of health states and health-related quality of life in children with chronic conditions. Child Care Health Dev. 2012;38:186-195.

[30] Kulkarni AV, Cochrane DD, McNeely PD, et al. Comparing children's and parents' perspectives of health outcome in paediatric hydrocephalus. Dev Med Child Neurol. 2008;50:587-592.

[31] Janse AJ, Sinnema G, Uiterwaal CS, et al. Quality of life in chronic illness: children, parents and paediatricians have different, but stable perceptions. Acta Paediatr. 2008;97:1118-1124.

[32] Chang PC, Yeh CH. Agreement between child self-report and parent proxy-report to evaluate quality of life in children with cancer. Psychooncology. 2005;14:125-134.

[33] Baggott C, Cooper BA, Marina N, et al. Symptom assessment in pediatric oncology: how should concordance between children's and parents' reports be evaluated? Cancer Nurs. 2014;37:252-262.

[34] Lim Y, Velozo C, Bendixen RM. The level of agreement between child self-reports and parent proxy-reports of health-related quality of life in boys with Duchenne muscular dystrophy. Qual Life Res. 2014;23:1945-1952.

[35] Storch EA, Rudy BM, Wu MS, et al. Moderators of impairment agreement among parent-child dyads in pediatric obsessive-compulsive disorder. J Psychopathol Behav Assess. 2015;37:318-328.

[36] Baxt C, Kassam-Adams N, Nance ML, et al. Assessment of pain after injury in the pediatric patient: child and parent perceptions. J Pediatr Surg. 2004;39:979-983.

[37] Buck D, Clarke MP, Powell C, et al. Use of the PedsQL in childhood intermittent exotropia: estimates of feasibility, internal consistency reliability and parent-child agreement. Qual Life Res. 2012;21:727-736.

[38] Feichtl RE, Rosenfeld B, Tallamy B, et al. Concordance of quality of life assessments following pediatric hematopoietic stem cell transplantation. Psychooncology. 2010;19:710-717.

[39] Miller L, Marnane K, Ziviani J, et al. The dimensions of mastery questionnaire in school-aged children with congenital hemiplegia: test-retest reproducibility and parent-child concordance. Phys Occup Ther Pediatr. 2014;34:168-184.

[40] Peny-Dahlstrand $M$, Krumlinde-Sundholm L, GosmanHedstrom G. Is autonomy related to the quality of 
performance of everyday activities in children with spina bifida? Disabil Rehabil. 2012;34:514-521.

[41] Taylor RM, Grieve A, Gibson F, et al. Parental assessment of adolescent quality of life: can it replace self-assessment? Qual Life Res. 2011;20:1715-1720.

[42] Zebracki K, Drotar D. Pain and activity limitations in children with Duchenne or Becker muscular dystrophy. Dev Med Child Neurol. 2008;50:546-552.

[43] Canavera KE, Wilkins KC, Pincus DB, et al. Parent-child agreement in the assessment of obsessive-compulsive disorder. J Clin Child Adolesc Psychol. 2009;38:909-915.

[44] Comer JS, Kendall PC. A symptom-level examination of parent-child agreement in the diagnosis of anxious youths. J Am Acad Child Adolesc Psychiatry. 2004;43:878-886.

[45] Kramer TL, Phillips SD, Hargis MB, et al. Disagreement between parent and adolescent reports of functional impairment. J Child Psychol Psychiatry. 2004;45:248-259.

[46] van der Meer M, Dixon A, Rose D. Parent and child agreement on reports of problem behaviour obtained from a screening questionnaire, the SDQ. Eur Child Adolesc Psychiatry. 2008;17:491-497.

[47] Nugent KL, Kline E, Thompson E, et al. Assessing psychoticlike symptoms using the BASC-2: adolescent, parent and teacher agreement. Early Interv Psychiatry. 2013;7:431-436.

[48] Salbach-Andrae H, Lenz K, Lehmkuhl U. Patterns of agreement among parent, teacher and youth ratings in a referred sample. Eur Psychiatry. 2009;24:345-351.

[49] Weems CF, Feaster DJ, Horigian VE, et al. Parent and child agreement on anxiety disorder symptoms using the DISC predictive scales. Assess. 2011;18:213-216.

[50] Clark BG, Magill-Evans JE, Koning CJ. Youth with autism spectrum disorders: self- and proxy-reported quality of life and adaptive functioning. Focus Autism Other Dev Disabil. 2015;30:57-64.
[51] Potvin MC, Snider L, Prelock PA, et al. Health-related quality of life in children with high-functioning autism. Autism. 2015;19:14-19.

[52] Grills $A E$, Ollendick TH. Issues in parent-child agreement: the case of structured diagnostic interviews. Clin Child Fam Psychol Rev. 2002;5:57-83.

[53] De Los Reyes A, Kazdin AE. Informant discrepancies in the assessment of childhood psychopathology: a critical review, theoretical framework, and recommendations for further study. Psychol Bull. 2005;131:483-509.

[54] Davis E, Nicolas C, Waters E, et al. Parent-proxy and child self-reported health-related quality of life: using qualitative methods to explain the discordance. Qual Life Res. 2007; 16:863-871.

[55] Ellert U, Ravens-Sieberer U, Erhart $M$, et al. Determinants of agreement between self-reported and parent-assessed quality of life for children in Germany-results of the German Health Interview and Examination Survey for Children and Adolescents (KiGGS). Health Qual Life Outcomes. 2011;9:102-112.

[56] Waters E, Stewart-Brown S, Fitzpatrick R. Agreement between adolescent self-report and parent reports of health and well-being: results of an epidemiological study. Child Care Health Dev. 2003;29:501-509.

[57] Shrout PE, Fleiss JL. Intraclass correlations: uses in assessing rater reliability. Psychol Bull. 1979;86:420-428.

[58] UNICEF. The Convention on the Rights of the Child [Internet]. United Nations Genaral Assembly; 1989. [cited 2015 Oct 2]. Available from: http://www.ohchr.org/ Documents/Professionallnterest/crc.pdf

[59] De Civita $M$, Regier D, Alamgir AH, et al. Evaluating healthrelated quality-of-life studies in paediatric populations: some conceptual, methodological and developmental considerations and recent applications. Pharmacoeconomics. 2005;23:659-685. 